\title{
A cross-sectional analysis of the prevalence of tooth agenesis and structural dental anomalies in association with cleft type in non-syndromic oral cleft patients
}

\author{
Dimitrios Konstantonis ${ }^{1,2^{*}}$, Alexandros Alexandropoulos ${ }^{1}$, Nikoleta Konstantoni ${ }^{3}$ and Maria Nassika ${ }^{1}$
}

\begin{abstract}
Background: The aim of this study was to investigate the prevalence of tooth agenesis, microdontia, and tooth malformation among non-syndromic oral cleft patients and their potential association with cleft type and gender.

Methods: Intraoral records and radiographs of 154 patients (97 males and 57 females) were examined. The variables assessed were tooth agenesis, microdontia, dental malformations, and cleft types. The statistics included chi-square and Fisher's exact tests as well as logistic regression to assess any mutual effects of gender and cleft type on the dental variables.

Results: Tooth agenesis occurred in $50 \%$ of the sample and microdontia in $18 \%$. Non-statistically significant odds ratios for the association of gender and cleft type with tooth agenesis were obtained. Tooth agenesis was substantially higher at the unilateral right $\mathrm{CL}+\mathrm{P}$ and the bilateral $\mathrm{CL}+\mathrm{P}$ in quadrant 1 and at the unilateral left $\mathrm{CL}$ $+\mathrm{P}$ and bilateral $\mathrm{CL}+\mathrm{P}$ in quadrant 2. It was also higher, at the isolated cleft palate (CP) in quadrants 3 and 4 . These results were attributed to teeth $22(31.8 \%)$ and $12(21.6 \%)$ in the maxilla and to teeth $35(6.1 \%)$ and 45 (5.4\%) in the mandible. In unilateral $\mathrm{CL}+\mathrm{P}$ patients, the cleft quadrant that presented tooth agenesis was associated with the side of the cleft.

Conclusions: Interdisciplinary treatment of the oral cleft patients should take into consideration the high prevalence of tooth agenesis and their association with the different cleft types. The most frequently affected teeth by cleft are by far the upper lateral incisors. Results indicate that tooth agenesis appears to be a genetically controlled anomaly related to the orofacial cleft development through various genetic links and not caused by the cleft disruptive process.
\end{abstract}

Keywords: Cleft lip and palate, Dental anomalies, Tooth agenesis, Microdontia

\section{Background}

Cleft lip and palate $(\mathrm{CL}+\mathrm{P})$ is the most common craniofacial birth defect in the world [1]. The average prevalence of cleft lip with or without cleft palate is 7.75 and 7.94 per 10,000 live births in the USA and worldwide, respectively, [2].

\footnotetext{
* Correspondence: dikons@dent.uoa.gr

${ }^{1}$ Department of Orthodontics, School of Dentistry, National and Kapodistrian University of Athens, 2 Thivon st, 11526 Athens, Greece

${ }^{2}$ Clinic of Orthodontics and Pediatric Dentistry, University of Zurich, Zurich,

Switzerland

Full list of author information is available at the end of the article
}

The most frequent dental anomaly among cleft patients is tooth agenesis [3-7]. The occurrence of tooth agenesis among cleft patients is markedly increased in comparison to the general, non-cleft population [3,6-11]. Additionally, dental anomalies appear more commonly in the cleft rather than the non-cleft area $[4,10,12-14]$. It is reported that the prevalence of left-sided clefts is higher than rightsided clefts; the cause still remaining unknown $[9,15]$. Data from the literature indicate that isolated cleft lip patients (CL) seem to be less affected by dental anomalies outside the cleft area compared to $\mathrm{CP}$ or $\mathrm{CL}+\mathrm{P}$ patients [7]. Furthermore, the permanent dentition seems to be 
more affected than the primary dentition in patients with unilateral and bilateral CL + P [13].

Other investigations suggest a link between the severity of the cleft type and the number of missing teeth as well as the incidence of dental anomalies [4, 12]. Still, the lateral incisor is reported as the most frequently missing tooth in cleft patients [3, 6, 13, 15, 16]. Also, according to a recent study, the prevalence of lateral incisor agenesis increases in respect to the severity of the cleft [16]. A much higher incidence of agenesis of second premolars was found in the maxilla rather in the mandible in $C L+P$ patients $[14,17]$. This agenesis was more frequently observed in the left side and was not gender- or jaw-dependent [9]. Also, contradictory results are reported regarding gender-dependent patterns in the distribution of dental anomalies $[4,18]$.

It is the aim of this study to identify a contemporary sample of cleft lip and/or palate patients and investigate the prevalence of tooth agenesis and structural dental anomalies and their possible association to the cleft type or gender. Therefore, the null hypothesis of this study was that tooth agenesis and dental structural anomalies are not different between the various types of oral clefts and gender.

\section{Methods}

The data of this study consisted of consecutive cleft patient records obtained from the graduate clinic of the Department of Orthodontics and Pediatric Dentistry of the School of Dentistry of the National and Kapodistrian University in Athens, Greece. An ethics and research committee approval was also obtained (ref. 312/21.09.2016).

Considering that the proportion of patients with tooth agenesis and structural dental anomalies approaches 60\%, we found that approximately 160 individuals are needed to ensure that a $99 \%$ confidence interval estimate of the proportion is within $10 \%$ of the true proportion [19].

By the end of 2016, a total of 154 cleft patient records were thoroughly examined for tooth agenesis and structural dental anomalies. All patients were born between 1977 and 2006 in Greece. Of them, 97 were males and 57 were females. The inclusion criteria were Caucasian male or female non-syndromic patients with complete records including dental casts, photos, and panoramic $\mathrm{x}$ rays; no history of permanent teeth extractions prior to the initial orthodontic screening; and no previous orthodontic treatment received. Third molars were excluded from our assessment. All patient records were taken prior to secondary alveolar bone grafting. Additionally, no pre-surgical orthopedics, gingivoperiosteoplasty or primary bone grafting were performed so that tooth agenesis as well as structural dental anomalies presented in this sample of patients could not be considered iatrogenic. In order to make sure that the agenesis of second premolars was not mistakenly noted due to individual variation, we evaluated all panoramic radiographs of patients older than 8 years of age. All patients received comprehensive orthodontic treatment in the Orthodontic Graduate Clinic.

Since orofacial cleft patients visit the orthodontic department quite early in life, adequate records of intraoral screening and radiographic assessment were readily available. Specifically, the panoramic and cephalometric radiographs along with the patient's intraoral photographs, dental casts, and charts were minutely examined. In addition, some of the patients' files contained a conebeam computed tomography, which was also assessed. In order to assess the intra and inter examiner repeatability, all the patients' records were reexamined by the principal investigator and by an independent examiner.

The types of orofacial clefts investigated in this research study were isolated cleft lip at the upper right side (CL U R), isolated cleft lip at the upper left side (CL $\mathrm{U}$ L), bilateral cleft lip and palate $(\mathrm{CL}+\mathrm{P} \mathrm{B})$, unilateral cleft lip and palate at the right side $(C L+P U R)$, and unilateral cleft lip and palate at the left side $(C L+P$ U L) and isolated cleft palate (CP). The dental anomalies examined included tooth agenesis, and teeth with morphological discrepancies in regard to mainly their shape and size (malformation and microdontia).

\section{Statistical analysis}

All analyses were performed using the Stata statistical package (Stata/SE 11.0. for Windows; Stata Corporation, College Station, TX, USA). For descriptive purposes, results are presented as frequency and percentages. Chisquare and Fisher's exact tests were applied to assess comparisons between tooth agenesis, structural dental anomalies, cleft types, and gender. Logistic regression was performed to further assess any mutually adjusted potential effects of gender and cleft type on tooth agenesis and microdontia and to examine potential confounding. Tooth analysis alone or through comparisons of maxillary and mandibular arches was further carried out using Fisher's exact test. The significance level was predetermined at $5 \%$. To assess intra and inter examiner repeatability, Cohen's Kappa statistical tests were performed. The reexamination of all 154 cases by the principal and a second investigator resulted in excellent intra and inter examiner agreement.

\section{Results}

Cleft distribution, tooth agenesis, and structural dental anomalies among patients

In a total of 154 cleft patients, all cleft types were present except CL U R. The most frequently observed cleft type was $\mathrm{CL}+\mathrm{P} \mathrm{U} \mathrm{L}(n=59 ; 38.3 \%)$, followed by $\mathrm{CL}+\mathrm{P} \mathrm{B}(n=39 ; 25.3 \%)$ and $\mathrm{CL}+\mathrm{P} \mathrm{U} \mathrm{R}(n=34 ; 22.1 \%)$. On the other hand, the least frequent cleft types were 
CP $(n=16,10.14 \%)$ and CL U L $(n=6 ; 3.9 \%)$. A higher incidence of CL + P U L was observed in men (44.3\%) compared to women (28.1\%), although the overall association between gender and cleft type was not statistically significant $(p=0.108)$ (Fig. 1).

The distribution of tooth agenesis and structural dental anomalies is presented in Table 1 overall and by gender. Of the 154 patients, 77 (50\%) presented with tooth agenesis, $28(18.2 \%)$ with microdontia and only one patient with malformation of one tooth. No gender differences occurred overall and for each separate dental anomaly.

Neither the frequency of tooth agenesis nor microdontia differed between male and female patients. Specifically, $29.9 \%$ of the patients had 1 and $14.3 \%$ had 2 teeth missing whereas $5.8 \%$ of the patients were found to have 3 or more missing teeth. Microdontia was found in $18.2 \%$ of the patients. Of these patients, $14.3 \%$ presented microdontia in 1 tooth and $3.9 \%$ in 2 or more teeth (Table 2).

\section{Association of tooth agenesis and structural dental anomalies with cleft and gender}

No tooth agenesis was observed among the 6 patients with $\mathrm{CL} \mathrm{U} \mathrm{L}$, and no microdontia among the 16 with CP. Still, no differences were found between the different types of clefts in regard to tooth agenesis $(p=0.111)$ and microdontia $(p=0.211)$ (data not shown). After excluding those cleft types with no dental anomalies from the corresponding analyses for tooth agenesis $(N=148)$ and microdontia $(N=138)$, we found that only in the $\mathrm{CL}+\mathrm{P} \mathrm{B}$ group, the male patients were missing significantly more teeth than the female patients $(p=0.047)$ (Figs. 2 and 3). To further explore any potential confounding, we assessed the mutually adjusted effects of gender and cleft type on the occurrence of tooth agenesis or microdontia through logistic regression. Females appeared to have a lower risk for tooth agenesis by $27 \%$ compared to men after controlling for cleft type, but the result did not reach statistical significance $(\mathrm{OR}=0.73$, 95\% CI 0.37-1.46). Neither gender nor cleft types were

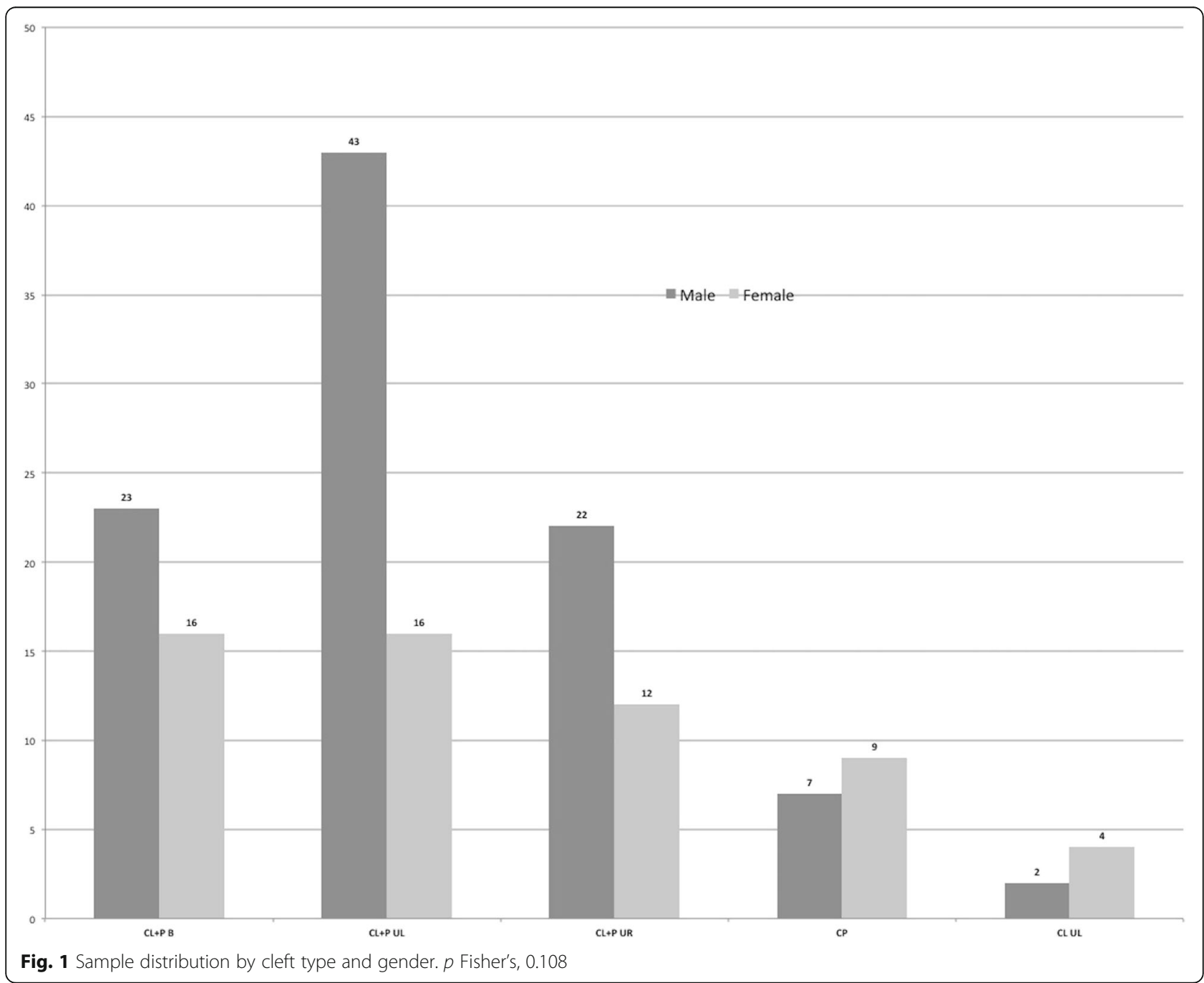


Table 1 Dental anomalies by gender and overall

\begin{tabular}{|c|c|c|c|c|c|c|c|}
\hline \multirow[b]{2}{*}{ Dental anomalies } & \multicolumn{2}{|c|}{$\begin{array}{l}\text { Total } \\
154 \\
\end{array}$} & \multicolumn{2}{|c|}{$\begin{array}{l}\text { Male } \\
97\end{array}$} & \multicolumn{2}{|c|}{$\begin{array}{l}\text { Female } \\
57\end{array}$} & \multirow[t]{2}{*}{$p$ value } \\
\hline & $N$ & $\%$ & $N$ & $\%$ & $N$ & $\%$ & \\
\hline Tooth agenesis & & & & & & & $0.243^{*}$ \\
\hline No & 77 & 50.0 & 45 & 46.4 & 32 & 56.1 & \\
\hline Yes & 77 & 50.0 & 52 & 53.6 & 25 & 43.9 & \\
\hline Microdontia & & & & & & & $0.875^{*}$ \\
\hline No & 126 & 81.8 & 79 & 81.4 & 47 & 82.5 & \\
\hline Yes & 28 & 18.2 & 18 & 18.6 & 10 & 17.5 & \\
\hline Malformation & & & & & & & $1.000^{* *}$ \\
\hline No & 153 & 99.3 & 96 & 99.0 & 57 & 100.0 & \\
\hline Yes & 1 & 0.7 & 1 & 1.0 & 0 & 0.0 & \\
\hline Overall & & & & & & & $0.256^{*}$ \\
\hline No & 56 & 36.4 & 32 & 33.0 & 24 & 42.1 & \\
\hline Yes & 98 & 63.6 & 65 & 67.0 & 33 & 57.9 & \\
\hline
\end{tabular}

"From chi-square test; ${ }^{* *}$ From Fisher's exact test

associated with tooth agenesis or structural dental anomalies ( $p$ values $>0.05$ ) (Table 3 ).

\section{Tooth agenesis, structural dental anomalies, and cleft type by tooth and by quadrant: inter-quadrant association}

The highest prevalence of tooth agenesis occurred for the maxillary left lateral incisor (22), the maxillary right lateral incisor (12), the maxillary right second premolar (15), the mandibular left second premolar (35), and the mandibular right second premolar (45) (Table 4). Both the upper lateral incisors and lower left second premolars were significantly missing in this sample of cleft patients. The upper right lateral incisor was found missing more in the CL + P R group (38.2\%); whereas the upper left lateral incisor was primarily missing in the $\mathrm{CL}+\mathrm{P} B$ group (43.6\%) and secondarily in the $\mathrm{CL}+\mathrm{P} \mathrm{L}$ group (40.7\%). Furthermore, the lower left second premolar was missing more in the CP group (25\%). The CL U L

Table 2 Frequency of tooth agenesis and microdontia

\begin{tabular}{clllllll}
\hline & Total & \multicolumn{5}{l}{ Male } & \multicolumn{3}{l}{ Female } & $p$ Fisher's \\
& 154 & & 97 & & 57 & \\
\hline Agenesis freq. & $N$ & $\%$ & $N$ & $\%$ & $N$ & $\%$ & \\
0 & 77 & 50.0 & 45 & 46.4 & 32 & 56.1 & 0.255 \\
1 & 46 & 29.9 & 28 & 28.9 & 18 & 31.6 & \\
2 & 22 & 14.3 & 16 & 16.5 & 6 & 10.5 & \\
$3+$ & 9 & 5.8 & 8 & 8.2 & 1 & 1.8 & \\
Microdontia freq. & & & & & & & 0.778 \\
0 & 126 & 81.8 & 79 & 81.4 & 47 & 82.5 & \\
1 & 22 & 14.3 & 15 & 15.5 & 7 & 12.3 & \\
$2+$ & 6 & 3.9 & 3 & 3.1 & 3 & 5.3 & \\
\hline
\end{tabular}

group of patients presented an intact alveolus and no missing teeth or teeth with structural dental anomalies. Microdontia occurred only for the maxillary central and lateral incisors. However, only the upper left lateral incisors presented microdontia, which was significantly larger for the CL + P L group $(p=0.028)$ (Table 5).

Table 6 presents the association between tooth agenesis by quadrant and by cleft type. Agenesis of teeth in the upper right quadrant (Q1) occurred mainly in the $\mathrm{CL}+\mathrm{P} \mathrm{R}$ patients $(44.1 \%, p=0.014)$. Similarly, agenesis of teeth in the upper left quadrant (Q2) occurred mainly in the CL + P B (48.7\%) and CL + P L (40.7\%) groups of patients $(p=0.003)$. With regard to the mandibular left (Q3) and right (Q4) quadrant, the CP patients were found missing more teeth in these quadrants $(p=0.027$ and $p=0.050$, respectively) than any other cleft group.

A strong association was found between cleft and non-cleft quadrants in regard to tooth agenesis. More specifically, the association was statistically significant between Q1 and Q2 $(p=0.003), \mathrm{Q} 1$ and Q3 $(p=0.051)$, and Q3 and Q4 $(p<0.001)$ (Table 7).

\section{Discussion}

The distribution of the cleft types between male and female patients did not vary significantly. These results are in concordance with other research reports [14]. Still, the majority of the patients belonged to the CL + P $\mathrm{L}$ group $(38.3 \%)$ in agreement with relative research investigations $[9,15,20]$.

In current literature, tooth agenesis is also reported as the most frequent dental anomaly among cleft patients [3-7]. Interestingly, in the $C L+P B$ group, the frequency of tooth agenesis was significantly higher among males. All the other cleft groups showed no differences in the distribution of dental anomalies neither among them nor between genders. Other authors have also reported no differences in dental anomalies between genders [14, 21].

Tooth agenesis in the non-cleft population ranges at considerably smaller numbers than the $50 \%$ found in our study. In a cross-sectional study conducted by Lagana [22] in a large sample of 5005 individuals, the prevalence of tooth agenesis was 7,1\%, which is in similar range with the reports of Rakhshan [23] (0.15-16.2\% excluding the third molars). Lagana [24] also reported that the missing dental units are often the distal teeth in each group of homogeneous teeth: the upper and lower third molars, lateral incisors, and lower second premolars.

A meta-analysis conducted by Polder [25] included 33 studies and investigated the prevalence of nonsyndromic tooth agenesis. The results showed that the prevalence of dental agenesis in females was 1.37 times higher than in males. Most individuals were missing one 


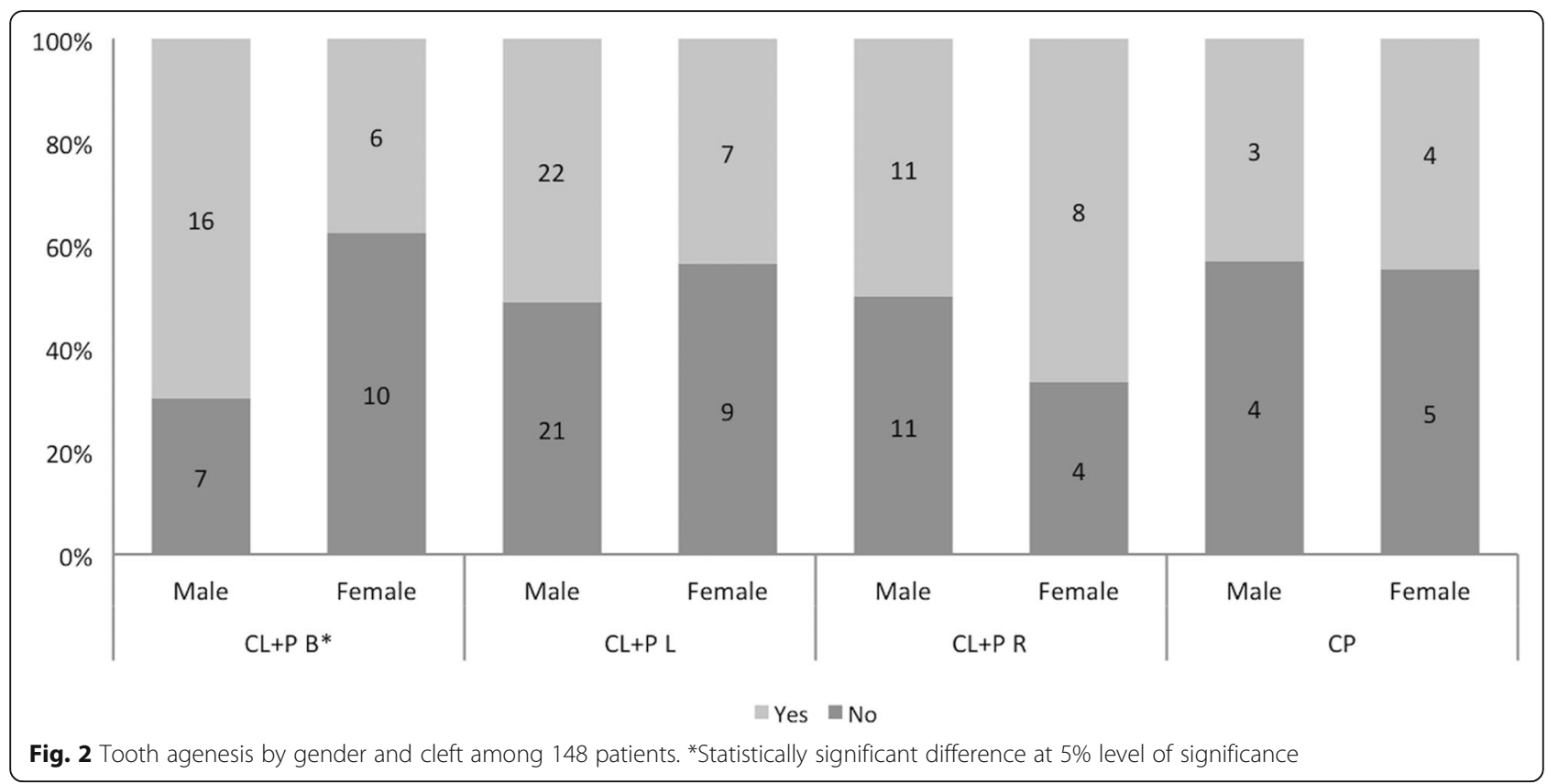

or two permanent teeth, with very few missing more than six. Also, the mandibular second premolar was the most affected tooth, followed by the maxillary lateral incisor and the maxillary second premolar.

The results of our study confirm Dermijian's reports who postulated that the mechanisms controlling dental development are independent of sexual and somatic maturity thus being influenced by other etiologic factors as clefts [26]. Baek and Kim also reported no differences in the distribution of dental anomalies between Korean male and female patients; whereas Wangsrimongkol et al. examining a sample of 280 Thai patients suggested a gender-dependent pattern in the agenesis of maxillary lateral incisors and maxillary second premolars $[4,18]$.

In regard to the association of the investigated dental anomalies with the type of cleft, our results showed no differences between the cleft groups coming, thus in contrast with those of Paranaiba et al., where patients with unilateral cleft lip and palate (CLP U) were more frequently affected by dental anomalies than those with bilateral cleft lip and palate (CLP B) [7]. In the same study, CLP U and CLP B were significantly more

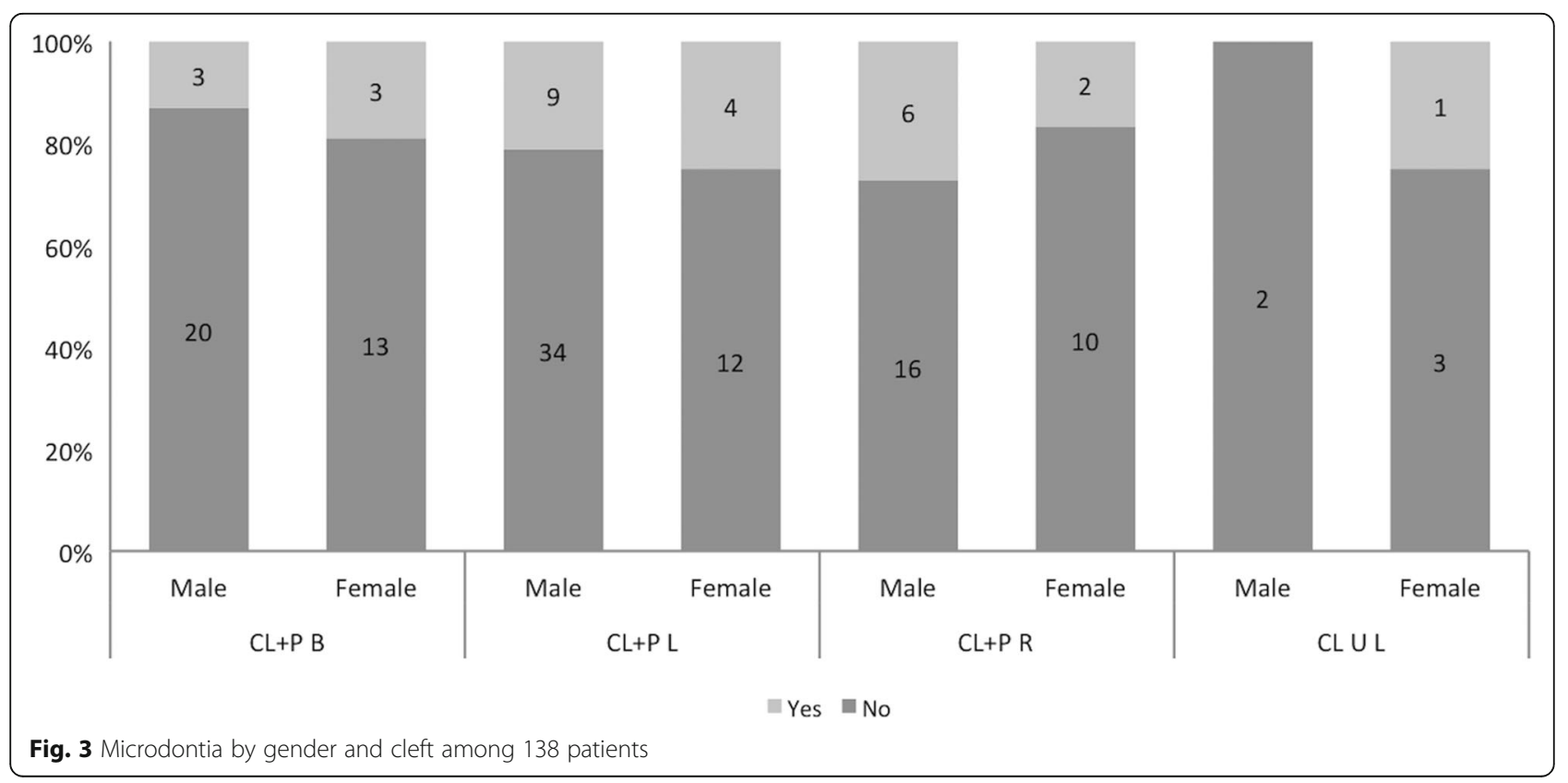


Table 3 Odds ratios ( $95 \% \mathrm{Cl}$ and $p$ ) for the association of tooth agenesis and microdontia with gender and cleft type (mutually adjusted)

\begin{tabular}{|c|c|c|c|c|c|c|c|c|}
\hline & \multicolumn{4}{|c|}{ Tooth agenesis $(N=148)$} & \multicolumn{4}{|c|}{ Microdontia $(N=138)$} \\
\hline & \multirow[t]{2}{*}{$\mathrm{OR}$} & \multicolumn{2}{|l|}{$95 \% \mathrm{Cl}$} & \multirow[t]{2}{*}{$p$} & \multirow[t]{2}{*}{$\mathrm{OR}$} & \multicolumn{2}{|l|}{$95 \% \mathrm{Cl}$} & \multirow[t]{2}{*}{$p$} \\
\hline & & Lower & Upper & & & Lower & Upper & \\
\hline \multicolumn{9}{|l|}{ Gender } \\
\hline Male & Ref & & & & Ref & & & \\
\hline Female & 0.73 & 0.37 & 1.46 & 0.375 & 1.11 & 0.46 & 2.70 & 0.812 \\
\hline \multicolumn{9}{|l|}{ Cleft type } \\
\hline CLP & Ref & & & & Ref & & & \\
\hline CLPL & 0.71 & 0.31 & 1.62 & 0.422 & 1.58 & 0.54 & 4.62 & 0.405 \\
\hline CLPR & 0.96 & 0.38 & 2.44 & 0.934 & 1.70 & 0.52 & 5.53 & 0.376 \\
\hline $\mathrm{CP}$ & 0.63 & 0.19 & 2.05 & 0.441 & (Omitted) & & & \\
\hline CLL & (Omitted) & & & & 1.07 & 0.10 & 10.98 & 0.954 \\
\hline
\end{tabular}

Table 4 Missing teeth by cleft type in a total of $148(C L \cup L$ patients did not present any missing teeth) cleft-patients

\begin{tabular}{|c|c|c|c|c|c|c|c|c|c|c|c|}
\hline \multirow[t]{2}{*}{ Tooth } & \multirow[t]{2}{*}{$N$} & \multirow{2}{*}{$\begin{array}{l}\text { Overall (148) } \\
\%\end{array}$} & \multicolumn{2}{|c|}{$C L+P B(39)$} & \multicolumn{2}{|c|}{$C L+P L(59)$} & \multicolumn{2}{|c|}{$C L+P R$ (34) } & \multicolumn{2}{|c|}{ CP (16) } & \multirow[t]{2}{*}{$p$ value } \\
\hline & & & $N$ & $\%$ & $N$ & $\%$ & $N$ & $\%$ & $N$ & $\%$ & \\
\hline 11 & 4 & 2.7 & 2 & 5.1 & 0 & 0.0 & 2 & 5.9 & 0 & 0.0 & 0.185 \\
\hline 12 & 32 & 21.6 & 11 & 28.2 & 6 & 10.2 & 13 & 38.2 & 2 & 12.5 & 0.007 \\
\hline 13 & 1 & 0.7 & 1 & 2.6 & 0 & 0.0 & 0 & 0.0 & 0 & 0.0 & 0.601 \\
\hline 14 & 2 & 1.4 & 2 & 5.1 & 0 & 0.0 & 0 & 0.0 & 0 & 0.0 & 0.238 \\
\hline 15 & 10 & 6.8 & 3 & 7.7 & 4 & 6.8 & 2 & 5.9 & 1 & 6.3 & 1 \\
\hline 16 & 0 & & & & & & & & & & \\
\hline 17 & 1 & 0.7 & 0 & 0.0 & 0 & 0.0 & 0 & 0.0 & 1 & 6.3 & 0.108 \\
\hline 21 & 2 & 1.4 & 2 & 5.1 & 0 & 0.0 & 0 & 0.0 & 0 & 0.0 & 0.238 \\
\hline 22 & 47 & 31.8 & 17 & 43.6 & 24 & 40.7 & 3 & 8.8 & 3 & 18.8 & 0.001 \\
\hline 23 & 1 & 0.7 & 0 & 0.0 & 1 & 1.7 & 0 & 0.0 & 0 & 0.0 & 1 \\
\hline 24 & 4 & 2.7 & 3 & 7.7 & 1 & 1.7 & 0 & 0.0 & 0 & 0.0 & 0.291 \\
\hline 25 & 6 & 4.1 & 3 & 7.7 & 1 & 1.7 & 1 & 2.9 & 1 & 6.3 & 0.433 \\
\hline 26 & 0 & & & & & & & & & & \\
\hline 27 & 1 & 0.7 & 0 & 0.0 & 0 & 0.0 & 0 & 0.0 & 1 & 6.3 & 0.108 \\
\hline 31 & 0 & & & & & & & & & & \\
\hline 32 & 1 & 0.7 & 0 & 0.0 & 0 & 0.0 & 0 & 0.0 & 1 & 6.3 & 0.108 \\
\hline 33 & 0 & & & & & & & & & & \\
\hline 34 & 0 & & & & & & & & & & \\
\hline 35 & 9 & 6.1 & 2 & 5.1 & 2 & 3.4 & 1 & 2.9 & 4 & 25.0 & 0.027 \\
\hline 36 & 0 & & & & & & & & & & \\
\hline 37 & 1 & 0.7 & 0 & 0.0 & 0 & 0.0 & 0 & 0.0 & 1 & 6.3 & 0.108 \\
\hline 41 & 1 & 0.7 & 0 & 0.0 & 0 & 0.0 & 0 & 0.0 & 1 & 6.3 & 0.108 \\
\hline 42 & 2 & 1.4 & 0 & 0.0 & 0 & 0.0 & 1 & 2.9 & 1 & 6.3 & 0.061 \\
\hline 43 & 0 & & & & & & & & & & \\
\hline 44 & 0 & & & & & & & & & & \\
\hline 45 & 8 & 5.4 & 3 & 7.7 & 2 & 3.4 & 1 & 2.9 & 2 & 12.5 & 0.375 \\
\hline 46 & 0 & & & & & & & & & & \\
\hline 47 & 0 & & & & & & & & & & \\
\hline
\end{tabular}


Table 5 Microdontia and cleft type by tooth in a total of 138 cleft patients

\begin{tabular}{|c|c|c|c|c|c|c|c|c|c|c|c|}
\hline \multirow[t]{2}{*}{ Tooth } & \multirow[t]{2}{*}{$N$} & \multirow{2}{*}{$\begin{array}{l}\text { Overall (138) } \\
\%\end{array}$} & \multicolumn{2}{|c|}{ CLL (6) } & \multicolumn{2}{|c|}{ CLP (39) } & \multicolumn{2}{|c|}{ CLPL (59) } & \multicolumn{2}{|c|}{ CLPR (34) } & \multirow[t]{2}{*}{$p$ value } \\
\hline & & & $N$ & $\%$ & $N$ & $\%$ & $\bar{N}$ & $\%$ & $\bar{N}$ & $\%$ & \\
\hline 11 & 4 & 2.9 & 0 & 0.0 & 2 & 5.1 & 0 & 0.0 & 2 & 5.9 & 0.232 \\
\hline 12 & 13 & 9.4 & 0 & 0.0 & 5 & 12.8 & 2 & 3.4 & 6 & 17.7 & 0.091 \\
\hline 21 & 4 & 2.9 & 1 & 16.7 & 1 & 2.6 & 1 & 1.7 & 1 & 2.9 & 0.296 \\
\hline 22 & 15 & 10.9 & 0 & 0.0 & 4 & 10.3 & 11 & 18.6 & 0 & 0.0 & 0.028 \\
\hline
\end{tabular}

affected by tooth agenesis than other cleft types. Additionally, Menezes and Vieira reported that in a sample of 146 cleft patients the CL+ P B patients presented more dental anomalies than individuals with incomplete CLP [27]. According to another group of researchers $\mathrm{CL}+\mathrm{P} \mathrm{U}$ had a higher prevalence of tooth agenesis, even in the non-cleft area, in comparison to the normal population [15].

In our sample, the upper lateral incisors followed by the upper right premolar were found missing most frequently in the cleft area. Still, a strong association between the side of the cleft and tooth agenesis was found for the two maxillary quadrants (Q1 and Q2) in $\mathrm{CL}+\mathrm{P} \mathrm{L}$ and in CL + P R patients and for the two mandibular quadrants (Q3 and Q4) in CP patients. In regard to the missing laterals, the findings are in accordance with a study conducted with 203 cleft patients in Brazil stating that agenesis of lateral incisors in CLP U patients was much more frequently noted in the cleft side rather than in the non-cleft side [14]. Still, several research projects conclude that agenesis occurs mainly at the cleft side and the most prevalent missing tooth is the lateral incisor [4, 10, 14-16]. Even in cases of isolated soft tissue cleft lip (the alveolus being intact), dental abnormalities, including tooth agenesis, were significantly more frequent in the cleft side [12]. In agreement with our results, several studies report the maxillary second premolars followed by their mandibular counterparts as the most frequent missing teeth outside the cleft area,

Table 6 Tooth agenesis by quadrant in maxilla and mandible and by cleft type

\begin{tabular}{|c|c|c|c|c|c|c|c|c|c|c|c|}
\hline & & & \multicolumn{2}{|c|}{$C L+P B$} & \multicolumn{2}{|c|}{$C L+P L$} & \multicolumn{2}{|c|}{$\mathrm{CL}+\mathrm{PR}$} & \multicolumn{2}{|l|}{$\mathrm{CP}$} & \multirow[t]{2}{*}{$p$ value } \\
\hline & & & $N$ & $\%$ & $N$ & $\%$ & $N$ & $\%$ & $N$ & $\%$ & \\
\hline \multirow[t]{4}{*}{ Maxilla } & Q1 & No & 26 & 66.7 & 50 & 84.8 & 19 & 55.9 & 13 & 81.3 & 0.014 \\
\hline & & Yes & 13 & 33.3 & 9 & 15.3 & 15 & 44.1 & 3 & 18.7 & \\
\hline & Q2 & No & 20 & 51.3 & 35 & 59.3 & 30 & 88.2 & 12 & 75.0 & 0.003 \\
\hline & & Yes & 19 & 48.7 & 24 & 40.7 & 4 & 11.8 & 4 & 25.0 & \\
\hline \multirow[t]{4}{*}{ Mandible } & Q3 & No & 37 & 94.9 & 57 & 96.6 & 33 & 97.1 & 12 & 75.0 & 0.027 \\
\hline & & Yes & 2 & 5.1 & 2 & 3.4 & 1 & 2.9 & 4 & 25.0 & \\
\hline & Q4 & No & 36 & 92.3 & 57 & 96.6 & 32 & 94.1 & 12 & 75.0 & 0.050 \\
\hline & & Yes & 3 & 7.7 & 2 & 3.4 & 2 & 5.9 & 4 & 25.0 & \\
\hline
\end{tabular}

*Fisher's exact test thus indicating a genetic link between cleft and tooth agenesis $[6,14,17]$.

However, the association between the maxillary right (Q1) and left quadrants (Q2) regarding tooth agenesis was found to be significant. A large percentage (52.5\%) of the 40 patients presenting with tooth agenesis in Q1 presented tooth agenesis also in Q2. These results indicate that if a patient presents with tooth agenesis in Q1

Table 7 Tooth agenesis between quadrants

\begin{tabular}{|c|c|c|c|c|c|c|c|}
\hline \multirow[t]{5}{*}{ Q1 vs Q2 } & & & \multicolumn{5}{|c|}{ Maxilla Q2 } \\
\hline & & & \multicolumn{2}{|l|}{ No } & \multicolumn{2}{|l|}{ Yes } & \multirow{2}{*}{$\begin{array}{l}p \\
0.003\end{array}$} \\
\hline & & & $N$ & $\%$ & $N$ & $\%$ & \\
\hline & Maxilla Q1 & No & 84 & 73.7 & 30 & 26.3 & \\
\hline & & Yes & 19 & 47.5 & 21 & 52.5 & \\
\hline \multirow[t]{5}{*}{ Q1 vs Q3 } & & & \multicolumn{4}{|c|}{ Mandible Q3 } & \\
\hline & & & \multicolumn{2}{|l|}{ No } & \multicolumn{2}{|l|}{ Yes } & $p$ \\
\hline & & & $N$ & $\%$ & $N$ & $\%$ & 0.051 \\
\hline & Maxilla Q1 & No & 110 & 96.5 & 4 & 3.5 & \\
\hline & & Yes & 35 & 87.5 & 5 & 12.5 & \\
\hline \multirow[t]{5}{*}{ Q1 vs Q4 } & & & \multicolumn{4}{|c|}{ Mandible Q4 } & \\
\hline & & & \multicolumn{2}{|l|}{ No } & \multicolumn{2}{|l|}{ Yes } & $p$ \\
\hline & & & $N$ & $\%$ & $N$ & $\%$ & 0.155 \\
\hline & Maxilla Q1 & No & 108 & 94.7 & 6 & 5.3 & \\
\hline & & Yes & 35 & 87.5 & 5 & 12.5 & \\
\hline \multirow[t]{5}{*}{ Q2 vs Q3 } & & & \multicolumn{4}{|c|}{ Mandible Q3 } & \\
\hline & & & \multicolumn{2}{|l|}{ No } & \multicolumn{2}{|l|}{ Yes } & $p$ \\
\hline & & & N & $\%$ & N & $\%$ & 0.480 \\
\hline & Maxilla Q2 & No & 98 & 95.2 & 5 & 4.8 & \\
\hline & & Yes & 47 & 92.2 & 4 & 7.8 & \\
\hline \multirow[t]{5}{*}{ Q2 vs Q4 } & & & \multicolumn{4}{|c|}{ Mandible Q4 } & \\
\hline & & & \multicolumn{2}{|l|}{ No } & \multicolumn{2}{|l|}{ Yes } & $p$ \\
\hline & & & $N$ & $\%$ & $N$ & $\%$ & 0.507 \\
\hline & Maxilla Q2 & No & 97 & 94.2 & 6 & 5.8 & \\
\hline & & Yes & 46 & 90.2 & 5 & 9.8 & \\
\hline \multirow[t]{5}{*}{ Q3 vs Q4 } & & & \multicolumn{4}{|c|}{ Mandible Q4 } & \\
\hline & & & \multicolumn{2}{|l|}{ No } & \multicolumn{2}{|l|}{ Yes } & $p$ \\
\hline & & & $N$ & $\%$ & $N$ & $\%$ & $<0.001$ \\
\hline & Mandible Q3 & No & 140 & 96.5 & 5 & 3.5 & \\
\hline & & Yes & 3 & 33.3 & 6 & 66.7 & \\
\hline
\end{tabular}


is more likely to have agenesis in Q2 compared to a patient who does not present with agenesis in Q1. Still, a strong association was found between Q1 and Q3 indicating that individuals with tooth agenesis at Q1 are more likely to have tooth agenesis also in Q3. To our knowledge in current literature, there are no similar reports examining the association of tooth agenesis quadrants.

The quadrant association findings indicate that tooth agenesis is not directly related to the disruptive osseous defect which occurs at the cleft side but is rather a genetically controlled anomaly related to the orofacial cleft possibly through multifactorial genetic links. These results confirm findings of previous research investigations, which suggest that tooth agenesis encompassing multiple missing teeth has been clearly identified under genetic control of multifactorial inheritance [28-30]. Several of these critical genetic controls assume a mutual part in the development of orofacial clefts [31].

The results of our study will be of valuable help to the clinicians who treat non-syndromic orofacial cleft patients in developing improved interdisciplinary treatment protocols. The high prevalence of tooth agenesis occurred especially in the maxillary arch could be further investigated with the use of the tooth agenesis code (TAC) method.

\section{Limitations of the study}

The limitations of this study can be primarily attributed to the small sample size especially for the groups of cleft lip only (CL U R and CL U L) and cleft palate only (CP). Still, oral clefts comprise a rare disease and collection of large samples can be very challenging. Furthermore, all patients were of Caucasian origin and this constitutes another limitation. In order to achieve an accurate representation of the different cleft types, distribution in non-syndromic oral cleft patients' further investigations should examine different ethnic groups and obtain larger sample sizes.

\section{Conclusions}

The results of this investigation showed that $50 \%$ of the oral cleft patients presented with tooth agenesis and $18 \%$ with microdontia.

The highest prevalence of tooth agenesis occurred for teeth $22,12,15,35$, and 45 .

No gender differences were noted overall and for each separate dental anomaly apart from the $\mathrm{CL}+\mathrm{P} \mathrm{B}$ patients where the frequency of tooth agenesis was significantly higher among men.

In $\mathrm{CL}+\mathrm{P} \mathrm{U}$ patients, the cleft quadrant presented tooth agenesis associated with the side of the cleft whereas $\mathrm{CP}$ patients showed tooth agenesis in the mandibular arch.
The significant association between quadrants with tooth agenesis and quadrants with no tooth agenesis indicates that tooth agenesis is not directly related to the disruptive osseous defect occuring at the cleft side but is rather a genetically controlled anomaly related to the orofacial cleft process.

\section{Authors' contributions \\ DK conceived the idea of the study, participated in its design and coordination, and wrote the manuscript. AA was responsible for acquisition of data and proofread the article. NK performed the statistical evaluation and participated in the design of the study. MN participated in data acquisition and helped in the interpretation of the results. All authors read and approved the final manuscript.}

\section{Competing interests}

The authors declare that they have no competing interests.

\section{Ethics approval and consent to participate}

An ethics and research committee approval from the Committee of Ethics of the Dental School of the National and Kapodistrian University of Athens in Athens, Greece, was obtained (ref. 312/21.09.2016) on October 24, 2016.

\section{Publisher's Note}

Springer Nature remains neutral with regard to jurisdictional claims in published maps and institutional affiliations.

\section{Author details}

${ }^{1}$ Department of Orthodontics, School of Dentistry, National and Kapodistrian University of Athens, 2 Thivon st, 11526 Athens, Greece. ${ }^{2}$ Clinic of Orthodontics and Pediatric Dentistry, University of Zurich, Zurich, Switzerland ${ }^{3}$ Center for Advanced Dental Education, Department of Orthodontics, Saint Louis University, Saint Louis, MO, USA.

Received: 28 December 2016 Accepted: 15 May 2017

Published online: 25 June 2017

\section{References}

1. Parameters for evaluation and treatment of patients with cleft lip/palate or other craniofacial anomalies. American Cleft Palate-Craniofacial Association. March, 1993. Cleft Palate Craniofac J. 1993;30(Suppl):S1-16.

2. Tanaka SA, Mahabir RC, Jupiter DC, Menezes JM. Updating the epidemiology of cleft lip with or without cleft palate. Plast Reconstr Surg. 2012;129:511e-8.

3. de Lima PR, Faria MD, de Castro Costa M, Vieira AR. Dental anomalies in children born with clefts: a case-control study. Cleft Palate Craniofac J. 2012; 49:e64-8.

4. Wangsrimongkol T, Manosudprasit M, Pisek P, Chittiwatanapong N. Prevalence and types of dental anomaly in a Thai non-syndromic oral cleft sample. J Med Assoc Thai. 2013;96 Suppl 4:S25-35.

5. Kuchler EC, da Motta LG, Vieira AR, Granjeiro JM. Side of dental anomalies and taurodontism as potential clinical markers for cleft subphenotypes. Cleft Palate Craniofac J. 2011:48:103-8.

6. Al Jamal GA, Hazza'a AM, Rawashdeh MA. Prevalence of dental anomalies in a population of cleft lip and palate patients. Cleft Palate Craniofac J. 2010; 47:413-20.

7. Paranaiba LM, Coletta RD, Swerts MS, Quintino RP, de Barros LM, MartelliJunior $\mathrm{H}$. Prevalence of dental anomalies in patients with nonsyndromic cleft lip and/or palate in a Brazilian population. Cleft Palate Craniofac J. 2013;50:400-5.

8. Jiroutova O, Mullerova Z. The occurrence of hypodontia in patients with cleft lip and/or palate. Acta Chir Plast. 1994;36:53-6.

9. Shapira $Y$, Lubit E, Kuftinec MM. Congenitally missing second premolars in cleft lip and cleft palate children. Am J Orthod Dentofacial Orthop. 1999; 115:396-400.

10. Aizenbud D, Camasuvi S, Peled M, Brin I. Congenitally missing teeth in the Israeli cleft population. Cleft Palate Craniofac J. 2005;42:314-7. 
11. Halpern RM, Noble J. Location and presence of permanent teeth in a complete bilateral cleft lip and palate population. Angle Orthod. 2010;80: 591-6.

12. Aizenbud D, Coval M, Hazan-Molina H, Harari D. Isolated soft tissue cleft lip: epidemiology and associated dental anomalies. Oral Dis. 2011;17:221-31.

13. Camporesi M, Baccetti T, Marinelli A, Defraia E, Franchi L. Maxillary dental anomalies in children with cleft lip and palate: a controlled study. Int Paediatr Dent. 2010;20:442-50.

14. Lourenco Ribeiro L, Teixeira Das Neves L, Costa B, Ribeiro Gomide M. Dental anomalies of the permanent lateral incisors and prevalence of hypodontia outside the cleft area in complete unilateral cleft lip and palate. Cleft Palate Craniofac J. 2003;40:172-5.

15. Bartzela TN, Carels CE, Bronkhorst EM, Kuijpers-Jagtman AM. Tooth agenesis patterns in unilateral cleft lip and palate in humans. Arch Oral Biol. 2013;58: 596-602.

16. Wu TT, Chen PK, Lo LJ, Cheng MC, Ko EW. The characteristics and distribution of dental anomalies in patients with cleft. Chang Gung Med J. 2011:34:306-14

17. Mikulewicz M, Oginski T, Gedrange T, Berniczei-Royko A, Prussak E. Prevalence of second premolar hypodontia in the Polish cleft lip and palate population. Med Sci Monit. 2014;20:355-60.

18. Baek SH, Kim NY. Congenital missing permanent teeth in Korean unilateral cleft lip and alveolus and unilateral cleft lip and palate patients. Angle Orthod. 2007:77:88-93.

19. Sullivan L. http://sphweb.bumc.bu.edu/otlt/mph-modules/bs/bs704_power/ BS704 Power printhtml. 28 May 2017.

20. Dewinter G, Quirynen M, Heidbuchel K, Verdonck A, Willems G, Carels C. Dental abnormalities, bone graft quality, and periodontal conditions in patients with unilateral cleft lip and palate at different phases of orthodontic treatment. Cleft Palate Craniofac J. 2003;40:343-50.

21. Ranta R. A comparative study of tooth formation in the permanent dentition of Finnish children with cleft lip and palate. An orthopantomographic study. Proc Finn Dent Soc. 1972;68:58-66.

22. Lagana G, Venza N, Borzabadi-Farahani A, Fabi F, Danesi C, Cozza P. Dental anomalies: prevalence and associations between them in a large sample of non-orthodontic subjects, a cross-sectional study. BMC Oral Health. 2017;17:62.

23. Rakhshan V. Congenitally missing teeth (hypodontia): a review of the literature concerning the etiology, prevalence, risk factors, patterns and treatment. Dent Res J (Isfahan). 2015;12:1-13.

24. Lagana G, Lombardi CC, Franchi L, Cozza P. Tooth agenesis: dento-skeletal characteristics in subjects with orthodontic treatment need. Eur J Paediatr Dent. 2011:12:17-20.

25. Polder BJ, Van't Hof MA, Van der Linden FP, Kuijpers-Jagtman AM. A metaanalysis of the prevalence of dental agenesis of permanent teeth. Community Dent Oral Epidemiol. 2004;32:217-26.

26. Demirjian A, Goldstein H, Tanner JM. A new system of dental age assessment. Hum Biol. 1973;45:211-27.

27. Menezes R, Vieira AR. Dental anomalies as part of the cleft spectrum. Cleft Palate Craniofac J. 2008;45:414-9.

28. Vastardis $\mathrm{H}$. The genetics of human tooth agenesis: new discoveries for understanding dental anomalies. Am J Orthod Dentofacial Orthop. 2000 117:650-6.

29. Kim JW, Simmer JP, Lin BP, Hu JC. Novel MSX1 frameshift causes autosomaldominant oligodontia. J Dent Res. 2006;85:267-71.

30. Dentino KM, Peck S, Garib DG. Is missing maxillary lateral incisor in complete cleft lip and palate a product of genetics or local environment? Angle Orthod. 2012;82:959-63.

31. Lidral AC, Moreno LM, Bullard SA. Genetic factors and orofacial clefting. Semin Orthod. 2008:14:103-14.

\section{Submit your manuscript to a SpringerOpen ${ }^{\circ}$ journal and benefit from:}

- Convenient online submission

Rigorous peer review

- Open access: articles freely available online

High visibility within the field

Retaining the copyright to your article

Submit your next manuscript at $>$ springeropen.com 